Bond University

Research Repository

\title{
A DIY, Project-based Approach to Teaching Data Journalism
}

\author{
Graham, Caroline
}

Published in:

Asia Pacific Media Educator

DOI:

$10.1177 / 1326365 \times 18768308$

Licence:

Other

Link to output in Bond University research repository.

Recommended citation(APA):

Graham, C. (2018). A DIY, Project-based Approach to Teaching Data Journalism. Asia Pacific Media Educator, 28(1), 67-77. https://doi.org/10.1177/1326365X18768308

\section{General rights}

Copyright and moral rights for the publications made accessible in the public portal are retained by the authors and/or other copyright owners and it is a condition of accessing publications that users recognise and abide by the legal requirements associated with these rights.

For more information, or if you believe that this document breaches copyright, please contact the Bond University research repository coordinator. 


\title{
A DIY, project-based approach to teaching data journalism
}

Caroline Graham, Senior Teaching Fellow (Communication and Media), Bond University.

cgraham@bond.edu.au

c/- Bond University Faculty of Society and Design,

Gold Coast,

Queensland 4229

(07) 55952538

\begin{abstract}
:
As a case study, this paper will illustrate how a project-based approach has addressed some of the challenges of embedding data journalism content into courses at a small Australian university. It will also identify some of the associated limitations and difficulties. Since 2013, Bond journalism students have undertaken five collaborative data-driven investigations, with a sixth underway in 2018. The project-based approach encourages resilience, creative problem solving and minimises students' aversion to maths and statistics, while empowering students to produce industry-standard work in an area of inexperience and discomfort. However, it is a reasonably resource-intensive approach, and would be difficult to replicate in a larger cohort.
\end{abstract}

Keywords: data journalism, networked journalism, journalism education, numeracy, quantitative literacy, authentic assessment. 


\section{Introduction: Data journalism as 'the new punk'}

Simon Rogers (2014, p. 31) has developed a wonderful-if unconventionaltheory of data journalism as "the new punk". The Guardian reporter-turned-dataeditor at Twitter highlights the parallels between the radical music genre (whose barrier to entry was as low as a guitar and the ability to play three chords) and data-driven reporting:

It represented a DIY ethos and a shake-up of the established order. It was a change. Crucial to it was the idea: anyone can do it.

Rogers (2014) argues that as free, user-friendly tools for data collection, analysis and presentation proliferate, it is no longer necessary to be a coder or a developer to be a data journalist: in essence, anyone can do it. The data is there, he suggests. The tools are there. It's an emerging field, where the rules are yet to be written in stone. Why not give it a go? Rogers does qualify these statements with a caveat: everyone may be able to do data journalism, but not everyone can do it well. It is nonetheless a helpful sentiment to take into a classroom, especially one in which students are notoriously maths-adverse (or worse, maths-illiterate); it is an especially heartening sentiment for lecturers struggling to upskill in a fast-changing sub-discipline that has been called "the single most important trend in media work today" (Culver, 2014, n.p.).

\section{The challenges of teaching data journalism}

Data journalism (DJ), alongside its precursor, computer-assisted reporting (CAR), presents specific challenges for journalism education. As early as 2008, 
Yarnall et. al. identified data analysis as one of the distinguishing features of "the most celebrated journalistic work". However, there was-even thenwidespread consensus that teaching data analysis was a 'daunting' task (Yarnall et. al. 2008, p. 147) and the authors attributed data analysis' positioning as a "much-neglected subset of CAR skills" in journalistic tuition to a range of factors, including: the risk of alienating 'math phobic' journalism students, the state of flux within industry, cultural resistance from within the academy, concerns about 'mission drift' away from basic writing skills, and the challenges of finding trained faculty to teach data analysis.

A decade later, DJ's important role in public interest and investigative journalism is perhaps even more widely acknowledged; however, the core challenges of teaching data-driven research methods remain largely constant, despite the availability of online tools that have made aspects of research, visualisation and analysis more accessible to newcomers. In a comprehensive review of the Australian tertiary sector's approach to teaching data journalism, Davis and Cullen (2016) found that although the majority of educators recognised the importance of the rapidly expanding field of DJ, there were a number of barriers to including or expanding its place in journalism programs, such as: students' quantitative literacy levels, maths aversion, lecturers' experience/training, and the logistics of embedding DJ teaching and assessment into already crammed courses and programs. To compound these challenges, the academy is playing catch-up with an industry that, itself, has a complex relationship with DJ. While organisations like the Knight Foundation have done important work in advancing the role of DJ as a central pillar of $21^{\text {st }}$ century digital democracy, its 
position in the day-to-day newsroom is less privileged. The expense of training specialist reporters and maintaining interdisciplinary, integrated data journalism teams has prevented major investigative DJ work from becoming common practice: "most media companies see data journalism as a cost rather than an investment" (Splendore et. al., 2016, p. 149).

Whilst the structures of a university make it hard to keep pace with fast-moving industry developments (Ghiglione, 2001), the academy is in other ways almost better placed to capitalise on and explore data-driven reporting than industry itself (Graham, 2015). Universities have inbuilt frameworks for interdisciplinary collaboration, access to specialised software and data collection/presentation tools, opportunities to undertake networked or collaborative research and access to tools, resources and experts in statistics and data analysis. Thus, despite the challenges, Australian and international universities are joining news organisations, not-for-profits and grass-roots community groups in offering data-driven reporting courses (for a survey of Australian university offerings, see Davis \& Cullen, 2016, and for recent international perspectives see, for example, Culver, 2014, Splendore et. al., 2016, and Nguyen \& Lugo-Ocando, 2016); this paper will explore one such course.

\section{Towards a project-based approach: A case study}

Using a case study approach, this paper will illustrate how project-based assessments have addressed some of the challenges of embedding data-driven reporting techniques into courses at a small Australian university. It will focus on teaching and assessment in the Investigative Journalism (IJ) course at Bond 
University. While some approaches to data, statistics and elements of quantitative literacy are taught in other parts of the journalism program at Bond, the bulk of the data-driven reporting work takes place in the IJ course, in which the major piece of assessment is a collaborative data-driven investigation involving all of the 15-25 students enrolled.

As context, Bond has a boutique journalism program with an emphasis on small class sizes, industry collaboration and flexible degree structures. While some students are enrolled in a full Bachelor of Journalism, others only complete a sixsubject journalism major as part of a Bachelor of Arts, Communication or Creative Arts. These conditions create their own, specific teaching challenges: the university has three points of entry a year, so classes have a mixture of experience levels and competencies and the goals and ambitions of students vary enormously. On the other hand, small class sizes (tutorials have fewer than 12 students) facilitate the integration of project-based assessment and industry collaboration, both of which: encourage student agency (Fook \& Sidhu, 2010); embed theory and context within practice (Wilkins, 1998) and increase graduate employability. The IJ course aims to integrate tradition and theory with practice and, ideally, help students create a substantial, publishable portfolio piece.

CAR and DJ are both a natural fit for any research methods course, and have been a component of the IJ course at Bond for more than a decade. However, the introduction of a specific DJ focus was as much a practical consideration as a conceptual refocussing of the program. Deep investigative work relies on established and trusted contacts, advanced interviewing skills and reporting 
experience, so how does a lecturer get 15-25 undergraduate students (some in their first year of studies) to produce publishable (or at least, portfolio-worthy) investigative reporting? The solution involved two components. First, the course would build on the rich tradition of collaborative journalism in Australia (see, for example, Birnbauer, 2001, or Bacon, 2011) and students would work in collaborative or networked teams. Secondly, the course would focus on data journalism as the foundational research method. The data and analysis could guarantee strong, exclusive stories, which students could then break into research areas and supplement with documents, interviews, analysis, visualisation and storytelling, later in the process. This approach addressed both the students' inexperience with interviewing, and their increasing anxiety about this process (see, for example, Price, 2013).

\section{The project as a teaching framework}

Since 2013, Bond journalism students have undertaken five collaborative datadriven investigations, with a sixth underway in 2018. Student feedback has been collected through subject and teaching evaluations, students' academic reflections, observation and informal communication with students and graduates, and this has been used to refine the subject content and teaching approach. Investigative project topics have ranged from Queensland's anti-gang legislation and an assessment of the youth justice system through to the creation of a Happiness Index to measure the quality of life and disadvantage across Australia. The methodology for the 2013 project, an audit of Australia's 150 federal Members of Parliament in the lead-up to the 2013 election, was able to be further developed for reuse by a second cohort, to cover the 2016 election. The 
frameworks for these investigations have been disseminated elsewhere (Graham, 2012, Graham, 2015 \& Graham, 2017) so this article will focus on the evolution of the project-based approach to teaching DJ and identify a series of factors that appear to contribute to a project's success, as well as some limitations, challenges, and future directions.

\section{How the project works}

While the IJ lectures cover investigative methods, ethics, theory, traditions and industry analysis, the tutorials simulate a newsroom environment for students to develop a major collaborative investigation. The early weeks of the semester are used to conceptualise and define the scope of the project. Students then collect and analyse data, contextualise it with interviews and other research, and write and visualise their findings. Although the project is collaborative, the students identify sub-topics and niches to specialise in. They share information and collaborate with students working on the same sub-topic, and must manage overlap between their research and stories.

The project is the major piece of assessment in the subject (60\%), but this is broken into micro-assessments, including: data collection, research plan, story draft, infographic or visualisation, research journal, academic reflection and final investigative package. Wherever possible, the lecturer aims to work with industry to offer students a publication opportunity at the end of the project.

\section{Project inception and topic choice}


DJ, at least as it functions within this project, has a tendency to be more exploratory than other kinds of investigative reporting, which usually begin with a hunch or tip-off and have a much clearer investigative trajectory. It can be a challenge to find data sets (or information that can be collected/collated into a database) that: will have currency at the semester's conclusion, will deliver a range of strong news leads (sufficient to divide amongst the students) and will sustain student engagement. In practice, this usually means choosing an area of research where the public interest value is high enough that if students begin with a broad, exploratory question (for example, 'Who are the best and worst MPs in parliament?', or 'What are Australia's most disadvantaged regions?') their findings will be newsworthy, whatever the result.

\section{Overcoming data-phobia}

In Davis and Cullen's (2016) research, students' reluctance to embrace datadriven methods is named as one of the key challenges in teaching DJ and while this is consistent with the teaching experience at Bond, a number of strategies have helped minimise 'maths-aversion' and 'data-photobia'. Online tools (such as percentage calculators, average finders) and teaching tools (such as Poll Everywhere) have made teaching quantitative literacy more accessible and engaging. However, perhaps the most successful approach thus far has been to use the project as a lens through which to teach DJ skills, and to encourage students to self-identify data-driven strategies as one of their chosen research methods. 
The major project is presented to students as an 'investigation', not as a 'datadriven investigation' (even though, in practice, it is very much the latter). In the early weeks (where students generate their collaborative research questions and investigative methodology) all discussion is framed in the context of their topic. They are presented with a core question (for example, 'Who are Australia's most and least active politicians, and how do we find them?') and the cohort generates a series of research questions and discusses strategies for exploring, measuring and evidencing happenings. As well as interviews and other research, students naturally self-identify a number a data-driven strategies for their investigation, well before anyone has mentioned statistics, maths, or data.

It is, at least initially, almost a guerrilla approach to teaching data-driven reporting. Naturally, specific content and context about DJ is provided, explicitly, later in the course, but by this point students are invested in their project and have already overcome some of their potential resistance to the methodology. The project-driven approach allows the lecturer to normalise DJ as one of a range of journalistic tools a reporter has access to; the methodology doesn't define the students' investigation, the research questions do.

Invoking Rogers' metaphor of data journalism as the new punk is also helpful in communicating the project to students, if (or when) doubts about DJ creep in during the investigation. A team of 20 reporters with 12 weeks to dive deeply into a topic is a resource any newsroom would envy, and the advantage of working with data is that even, despite their relative inexperience, the students are still on an even playing field with many established journalists when it comes 
to data-driven reporting. There is agency in the choice to use data, and it can be both empowering and exciting.

\section{Student involvement in research design}

One of the most challenging elements of a data-driven investigation is conceptualising a research strategy that will provide meaningful and reliable results and conclusions. This design process is more closely aligned with academic research strategies than journalistic practice. Yarnall et. al. (2008, p. 147) suggest that: "Research methods classes too often teach technology use'how to do rather than how to think'." It is easy to see why; the research design process is difficult to teach, outside of a project-based approach or a series of specialist methods courses.

To create critical journalists in almost any field, Nguyen and Lugo-Ocando (2016, p. 5) suggest "permanent determination to question data and a basic level of statistical reasoning" is a necessary starting point, as well as the ability:

to use logical, valid reasoning and journalistic scepticism to (a) find and acquire data, (b) explore and evaluate their real meaning, (c) investigate non-numerical factors shaping them and (d) report them in a balanced, fair, accurate, accessible and engaging manner.

In many ways, this is the central aim of the IJ project and for this reason, it has been important to include students in the research design process. In a news conference format, the class considers some of the best ways to measure and 
evidence a phenomenon (e.g. political engagement or juvenile offending), and examines the potential gaps and weaknesses in the data. They begin to debate and ask questions: Does giving a lot of speeches make someone a better politician or just a louder one? Are some speeches more valid than others? Can we find out what each MP is talking about? What work might a politician do that isn't captured in the data?

This kind of critical engagement with the data takes place throughout the project: during the methodology design, data collection, data analysis, planning and researching the stories, visualising the data and reporting findings. The cohort naturally treats the yet-to-be-collected data as they would any other source: they ask questions of it; consider its agendas, weaknesses and blind spots; are critical of it; examine its biases; contextualise it; and cross-check it against other sources.

\section{The DIY ethos}

While the course provides tools, structures and assistance, the project-based approach encourages students to take responsibility for the project direction and to problem-solve their way through issues they encounter in the research process. The assessment encourages resourcefulness, creativity and tenaciousness. Student must develop an understanding of the proficiencies they have (individually and collectively) and overcome the gaps in their skills and resources through collaboration. 
For example, the lectures and tutorials cover some frameworks for data analysis using Excel, and online courses and tutorials (for example, Lynda.com or YouTube tutorials) can help with intermediate analysis, supported by teaching staff. Complex or technical analysis (for example, correlations) can still be achieved through enlisting an expert with access to specialist software; fortunately, a university is full of such experts. In this case, the students must still develop the questions that drive the specialist data analysis, even if they do not conduct the analysis themselves, to ensure they are active participants and collaborators in this facet of the process.

\section{Manual vs automatic data collection}

In terms of research design, the most successful projects over the last six years have involved a mixture of hand-collected/coded data and open source or scraped data (using a crawler like import.io). This is perhaps a counter-intuitive finding, given the increasing number of readily-available data sets and the availability of excellent drag-and-drop web crawlers. However, despite its potential to be monotonous, manual data coding activities are often identified by students as a highlight of the course and seeing the data at a micro-level helps the students understand more complex spreadsheets. In some ways, students approach data as an exercise in translation, and the act of translating information to data is perhaps more accessible than the reverse. Even a simple, one-hour data collection exercise, if tied to the project outcomes, helps to explain the nature of data and to familiarise students with how it can be structured. As a bonus, hand-coded data is also exclusive data. One student (undergraduate student feedback, 2014) said: "I really enjoyed the data-mining aspect of the 
project, which I was definitely surprised about. While [coding] into Microsoft Excel was time-consuming and a little boring, it was gratifying knowing that our work was going to produce data that hadn't been seen before."

\section{Visualisations}

There is not scope within the program to design complex visualisations or code a visualisation or interactive from scratch, so online tools are an enormous asset. Getting each student to choose a free, online tool and visualise an element of their research is a worthwhile exercise, not just because it exposes students to some techniques and frameworks for visualisations, but also because it intensifies students' connection to the data. The visualisation process often prompts students to ask deeper questions about the data, and come to different conclusions about their results. One student wrote, in their academic reflection (2014), that: “...visualising the data was the first time I really understood the story it was telling. It made me really think about each line on the spreadsheet and what it really means." In some cases, the cohort has collaborated with a multimedia and design class to design a more complex interactive; the journalists brief the designers, who do the design, programming and coding.

\section{The benefits and challenges of the project-based approach}

This project-based approach to teaching DJ outlined above is by no means sufficient training to create specialised data journalists. However, over the course of six years and as many projects, it has a reasonably well established track record of producing reporters who have a substantial and largely positive experience with data-driven reporting. Comments from undergraduate students, 
in their evaluations and reflections, tend to focus on the utility of the task and its potential benefits in industry:

- It taught me a valuable lesson; in that one data mining mission can provide multiple leads for stories. If you think there are no stories out there and the world seems a bit boring: dig, search, compile a series of stats and it can lead you to some ammunition for a killer story (2016).

- As the media market shifts to an online audience, I consider [data journalism and visualisation] a valuable tool to boost my skills and career (2015).

- The most valuable investigative tool I have garnered from this exercise is the skill of being able to read data, in the sense that by changing the way pieces of information sit next to each other, you can have an entirely new outcome (2014).

- The whole experience, while initially daunting, was really rewarding. I learned a lot about the value of effective research, interviewing, the use of graphics, and my own abilities. While there was some apprehension and challenges along the way, I am proud of the article we have produced (2014).

Despite their inexperience, students produce industry-standard work; many of the collaborative investigations have been published by news organisations, including Crikey, APN Australian Regional Media and The Guardian Australia. The students' involvement in the entire DJ research process-from research design to execution-seems to increase engagement and motivation. Perhaps most importantly, the structure of the project encourages a collaborative mindset (within and external to the cohort) and a resourceful approach to roadblocks and limitations. In addition, students self-report in reflections and subject evaluations that the emphasis on data-driven reporting has improved their numerical and statistical literacy more generally.

The emphasis on data logic, literacy, scepticism and research strategy is also an approach that is likely to age well. While data journalism technologies and skills are changing rapidly, the ability to problem-solve and collaborate through 
investigative roadblocks to find innovative solutions will retain its value. It is also hoped that a positive, can-do, DIY approach to data demystifies it and opens up opportunities for students or graduates to further develop this skillset.

From a practical perspective, the project-based approach to teaching DJ has allowed teaching staff to upskill at a natural pace, learning more with each new project. Its integration with other journalistic research methods also means that teaching DJ is not at the expense of other coursework components.

However, there are some limitations to this approach, which is by no means a substitute for specialist training in coding and programming. Because the project-based learning is an applied teaching technique, the nature of each project dictates the areas of teaching focus-in terms of content, data, collection methods and analysis. Each year the content varies, and students get a taste of a range of DJ techniques but are not exposed to the full suite of tools and strategies available. The project would also be difficult to replicate with a bigger cohort; individualised consultation, feedback and support are necessary to offset the many challenges students face throughout the reporting experience. It is also worth noting that the changing nature of the project is time and resource intensive because so much of the content/assessment frameworks require updating (or, just as often, must be recreated entirely) for each new iteration. On this note, there may be scope to better collaborate across institutional boundaries, and to share-not just the learnings and outcomes of teaching within this space, but also the frameworks and methodologies underpinning data-driven projects, both with other universities, and to open-source these 
approaches so they are available to industry to use, learn from and adapt for future projects.

\section{Conclusions}

Much is made of the fear of data journalism. However, there is, within that fear, an opportunity for journalism educators and students alike. As Rogers says, "data journalism is a great leveller." As students and lecturers grapple with data journalism, newsrooms and journalists face similar challenges in adjusting to data and its impact on news. In the wider, fast-changing news landscape, an intrepid spirit, the ability to adapt, a willingness to upskill and an enthusiasm for new modes and models of research and storytelling are all enormous assets to a reporter. Data journalism offers opportunities to teach-and model—these characteristics, in a field where the norms and codes of practice are still being established and there is scope not to be expert but instead, to be adventurous.

\section{References}

Bacon, W. (2011). Investigative journalism in the academy-possibilities for storytelling across time and space. Pacific Journalism Review, 17(10), pp. 45-66.

Birnbauer, B. (2011). Student muckrakers: Applying lessons from non-profit investigative reporting in the US. Pacific Journalism Review, 17(1), pp. 3744.

Culver, K. B. (2014) Special series: Teaching data journalism. PBS MediaShift. Available at: http://mediashift.org/2014/07/special-series-teaching-datajournalism/ (accessed 25 February 2018).

Davis, K. \& Cullen, T. (2016). Data journalism classes in Australian universities: Educators describe progress to date. Asia Pacific Media Educator, 26(2), pp. 132-147.

Fook, C. Y., \& Sidhu, G. K. (2010). Authentic assessment and pedagogical strategies in higher education. Journal of Social Sciences, 6(2), pp. 153-161.

Ghiglione, L. (2001). The splendor of our failures. Journalism and Mass Communication Educator, 56(4), pp. 14-16. 
Graham, C. (2017). How to teach data journalism to the data-terrified. Walkley Magazine, 88, pp. 16-17.

Graham, C. (2015). By the numbers: Data journalism projects as a means of teaching political investigative reporting. Asia Pacific Media Educator, 24(2), pp. 247-261.

Graham, C. (2012). Real-life reporting: Authentic journalism assessment, student motivation and active learning. In K. Wood, D. Knight and S. Kinash (Eds), Scholarship of teaching and learning @ Bond (pp. 94-105). Gold Coast, QLD, Australia: Office of Teaching and Learning, Bond University.

Nguyen, A. \& Lugo-Ocando, J. (2016). The state of data and statistics in journalism and journalism education: Issues and debates. Journalism, $17(1)$, pp. 2-17.

Price, J. (2013). 'I can't wait til I'm an actual journalist': How students become journalists (unpublished Master of Arts thesis). University of Technology, Sydney.

Rogers, S. (2014). Data journalism is the new punk. British Journalism Review, 25(2), pp. 31-34.

Splendore, S., Salvo, P. D., Eberwein, T., Groenhart, H., Kus, M., \& Porlezza, C. (2016) Educational strategies in data journalism: A comparative study of six European countries. Journalism, 17(1), pp. 138-152.

Wilkins, D. M. (1998). Authentic assessment in a competitive sector: Institutional prerequisites and cautionary tales. Journalism and Mass Communication Educator, 53(1), pp. 64-73.

Yarnall, L. Johnson, J. T., Rinne, L., \& Ranney, M. A. (2008). How post-secondary journalism educators teach advanced CAR data analysis skills in the digital age. Journalism \& Mass Communication Educator, 63(2), pp. 146-164. 